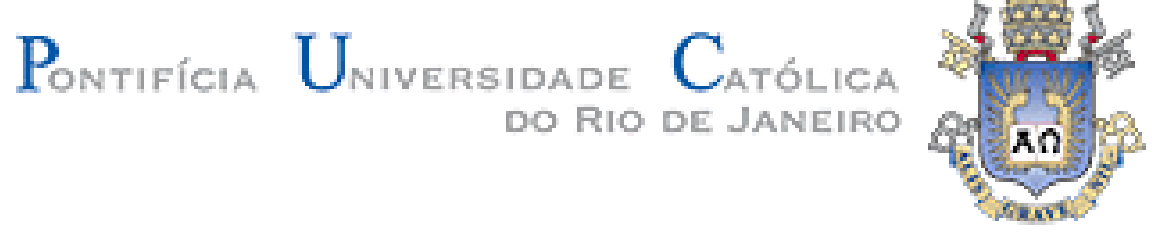

Ricardo Valadão Siqueira Matos

IMAGENS DO FUNK NO CINEMA NACIONAL: estereótipos e linhas de fuga nas representações cinematográficas do baile funk

Dissertação de Mestrado

Dissertação apresentada ao Programa de Pósgraduação em Comunicação Social da PUC-Rio como parte dos requisitos parciais para a obtenção do título de Mestre em Comunicação Social.

Orientadora: Andréa França Martins

Rio de Janeiro, Dezembro de 2008 
Ricardo Valadão Siqueira Matos

\section{IMAGENS DO FUNK NO CINEMA NACIONAL: estereótipos e linhas de fuga nas representações cinematográficas do baile funk}

Dissertação apresentada como requisito parcial para obtenção do grau de Mestre pelo programa de Pós-Graduação em Comunicação Social do Departamento de Comunicação Social do Centro de Ciência Humanas da PUC-Rio. Aprovada pela Comissão Examinadora abaixo assinada.

Profa. Andréa França Martins Orientadora

Departamento de Comunicação Social - PUC-Rio

Micael Herschmann ECO-UFRJ

Vera Lucia Follain de Figueiredo Departamento de Comunicação Social - PUC-Rio

Adriana Braga Departamento de Comunicação Social - PUC-Rio

Nizar Messari Coordenador Setorial do Centro de Ciências Sociais - Puc-Rio

Rio de Janeiro, 27 de Dezembro de 2008 
Todos os direitos reservados. É proibida a reprodução total ou parcial do trabalho sem autorização do autor, do orientador e da universidade.

\section{Ricardo Valadão Siqueira Matos}

Graduou-se em Filosofia pela Universidade do Estado do Rio de Janeiro em 2003. Concluiu o curso de Especialização em Literatura, Memória Cultural e Sociedade pelo CEFET-CAMPOS em 2006. Participou de diversos congressos e seminários assim como publicou textos atinentes aos estudos de comunicação, cultura, filosofia e história.

Ficha Catalográfica

Matos, Ricardo Valadão Siqueira

Imagens do funk no cinema nacional : estereótipos e linhas de fuga nas representações cinematográficas do baile funk / Ricardo Valadão Siqueira Matos ; orientadora: Andréa França Martins. -2008.

134 f. : il.(color.) ; $30 \mathrm{~cm}$

Dissertação (Mestrado em Comunicação Social)Pontifícia Universidade Católica do Rio de Janeiro, Rio de Janeiro, 2008.

Inclui bibliografia

1. Comunicação social - Teses. 2. Funk carioca. 3. Periferia. 4. Mídia. 5. Cinema. 6. Juventude. I. Martins, Andréa França. II. Pontifícia Universidade Católica do Rio de Janeiro. Departamento de Comunicação Social. III. Título. 
Para minha família e meus alunos de Macaé.

Para Pedro (In Memoriam) 


\section{Agradecimentos}

À Deus, pela vida que tenho.

À minha orientadora, professora Andréa França Martins, pela atenção e seriedade oferecida às minhas reflexões.

Aos professores do Mestrado em Comunicação Social da PUC-Rio, em especial à professora Vera Lúcia Follain de Figueiredo, que sempre se mostrou interessada pelo tema.

Aos professores que participaram da banca exa minadora.

Aos meus colegas de Mestrado, em especial à Roberta Giannini, pelas dicas e textos enviados.

Às minhas eternas orientadoras, Maria Regina Cândido (UERJ) e Analice de Oliveira Martins (CEFET-CAMPOS) que me introduziram no universo da pesquisa acadêmica. 
Às minhas amigas Carine Cadilho, pelo material fornecido, Soraya Cristina e Ana Eliza Adami pelo apoio.

À Jorcelina pela revisão do texto.

À Direção do Templo Glauber, pela colaboração ao exibir para mim o filme Câncer.

Aos meus amigos e familiares pelo apoio.

À PUC-Rio, pelos auxílios concedidos, sem os quais esta pesquisa não teria sido realizada. 


\section{Resumo}

Matos, Ricardo Valadão Siqueira; França, Andréa (orientadora). Imagens do funk no cinema nacional: estereótipos e linhas de fuga nas representações cinematográficas do baile funk. Rio de Janeiro; 2008. 134p. Dissertação de Mestrado. Departamento de Comunicação Social. Pontifícia Universidade Católica do Rio de Janeiro.

Um dos principais aspectos da sociedade brasileira contemporânea é a grande produção e proliferação de imagens, discursos e narrativas sobre a periferia e a sua cultura. Os meios de comunicação de massa se apresentam soberanamente como os mais legítimos divulgadores da realidade da periferia para o imaginário social. Mas podemos levantar os seguintes questionamentos: como a mídia representa a cultura da periferia? Há uma glamourização ou uma demonização dos elementos da favela? Que imagens escapam dos clichês midiáticos? Esta pesquisa tem como objetivo analisar as imagens e os discursos da mídia sobre o funk carioca. Buscaremos evidenciar os estereótipos imagéticos do cinema nacional que associam o movimento funk à criminalidade, ao tráfico de drogas, à violência, ao sexo precoce e à irresponsabilidade juvenil.

\section{Palavras-chave}

Funk carioca; Periferia; Mídia; Cinema; Juventude 


\section{Abstract}

Matos, Ricardo Valadão Siqueira; França, Andréa (advisor). Funk images in the national movies: stereotypes and escape lines in the funk ball pictures representations. Rio de Janeiro; 2009. 134p. MSc. Dissertation. Departamento de Comunicação Social. Pontifícia Universidade Católica do Rio de Janeiro.

One of the main aspects of contemporary Brazilian society is the major production and proliferation of images, speeches and narratives about the periphery and its culture. The mass communication media presents itself as the most legitimate reality advisers of the periphery to the social imaginary. But we can raise the following questions: how the media represents the culture of the periphery? Is there a kind of glamour or is there a demonization of the elements of the slum? Which images are beyond the media cliches? This research aims to analyze the pictures and speeches of the media on the "carioca" funk. We highlight the stereotypes imaging of local cinema involving the funk movement against crime, drug dealing, violence, sex and irresponsibility on precocious youth.

\section{Keywords}

Funk carioca - periphery -media - cinema - young people 


\section{Sumário}

$\begin{array}{ll}\text { 1. Introdução } & 11\end{array}$

2. Estigmatização do Funk na Mídia Impressa:

entre o glamour e a demonização

3. Estéticas da Periferia:

as representações da favela no Cinema Novo e no Cinema da Retomada

4. Representações Cinematográficas do Funk Carioca:

a construção de estereótipos e linhas de fuga das imagens do bailes funk 87

5. Considerações Finais 112

$\begin{array}{lr}\text { 6. Bibliografia } & 119\end{array}$

$\begin{array}{lr}\text { 7. Filmografia } & 132\end{array}$ 


\title{
Epígrafe
}

\begin{abstract}
A alienação do espectador em favor do objeto contemplado (o que resulta de sua própria atividade inconsciente) se expressa assim: quanto mais ele contempla, menos vive; quanto mais aceita reconhecer-se nas imagens dominantes da necessidade, menos compreende sua própria existência e seu próprio desejo. Em relação ao homem que age, a exterioridade do espetáculo aparece no fato de seus próprios gestos já não serem seus, mas de um outro que os representa por ele. É por isso que o espectador não se sente em casa em lugar algum, pois o espetáculo está em toda parte.
\end{abstract}

Guy Debord

Assim, somente uma cultura da fome, minando suas próprias estruturas, pode superar-se qualitativamente e mais nobre manifestação cultural da fome é a violência.

Glauber Rocha 